\title{
Sob a sombra de Carmen Miranda e do carnaval: brasileiras em Los Angeles*
}

\author{
Bernadete Beserra**
}

\begin{abstract}
Resumo
Neste artigo, analiso como brasileiras de classes média e média alta em Los Angeles lidam com o fenômeno da exotização das suas imagens. Observo que, embora originalmente articuladas a partir de Hollywood (Carmen Miranda) nos limites da hierarquia entre as nações e do colonialismo, essas imagens são hoje alimentadas e recriadas também pelos próprios brasileiros. Uma das idéias centrais que defendo aqui é que embora tais imagens inicialmente restrinjam a ação das brasileiras, uma vez que sempre impõem o diálogo com os seus conteúdos, elas não o fazem permanentemente, ou seja, no processo de integração há espaço para a negociação de outras imagens e conteúdos e isto depende de fatores que vão além da exotização em si.
\end{abstract}

Palavras-chave: Brasileiras Imigrantes, Brasileiros nos Estados Unidos, Exotização, Negociação de Imagens.

\footnotetext{
* Recebido para publicação em junho de 2006, aceito em novembro de 2006. Versões preliminares deste artigo foram apresentadas nas conferências da Associação Alemã de Investigação sobre a América Latina (ADLAF), em novembro de 2003, e da Latin American Studies Association (LASA), em março de 2006.

*** Professora Adjunta da Faculdade de Educação, Universidade Federal do Ceará. bernadetebeserra@yahoo.com.br
} 
Sob a sombra de Carmen Miranda e do carnaval

Under the Shadow of Carmen Miranda and Carnival: Brazilian Women in Los Angeles

\begin{abstract}
This article discusses how middle and upper-middle class Brazilian women deal with their exoticized images in Los Angeles. It points out that although originally articulated from Hollywood (Carmen Miranda), within the limits of the hierarchy of nations and colonialism, today these images are also fed and recreated by Brazilians. One of the central ideas presented is that, despite constraining the movements and actions of the women, imposing on them the need to dialogue with their content, these exotic images do not do it permanently. In other words, in the process of integration, there is always room for negotiation of other images and contents that depend on factor other than exoticization itself.
\end{abstract}

Key Words: Brazilian Immigrant Women, Brazilians in the United States, Exoticization, Negociation of Images. 
Bernadete Beserra

\section{Introdução}

Os americanos acham que o Brasil é só festa, tempo bom e sexo! Para eles o Brasil é uma grande orgia: as mulheres andam nuas e todo mundo está sempre transando numa festa que não acaba nunca...

Curiosamente não há diferença entre o que Ivan Becker jornalista brasileiro que entrevistei em Los Angeles, no dia 14 de abril de 1999 - descreve como uma fantasia americana do Brasil e a crença espalhada na Europa do século XVII, de acordo com a qual não existe pecado do lado debaixo do Equador. ${ }^{1}$

O Brasil de hoje, como a então desconhecida América tropical do século XVII, é imaginado como um paraíso terrestre: sem leis, sofrimento, trabalho ou castigo: "o Éden tropical para o qual muitos de nós, em algum momento, secretamente sonhamos escapar", confidencia Joseph Page no seu livro The Brazilians. Ele também acrescenta que as coisas têm mudado ultimamente e da década de 1990 para cá

a menção ao Brasil evoca imagens de crianças de rua sendo perseguidas e assassinadas por esquadrões da morte compostos por policiais (nas suas horas ou dias de folga) $e$ de serras elétricas e fogo destruindo a maior floresta úmida sobrevivente do mundo (Page, 1995:1).

Nem a imagem da América do século XVII nem a do Brasil de hoje valorizam os conteúdos estáveis das realidades que as inspiram porque imagens ou preferências exóticas são produzidas "exclusivamente pela sua relação com o observador", explica Todorov (1993:264). O que importa são os interesses, desejos e projeções do observador $e$ a sua atração por certos conteúdos à

1 Antes de portugueses e espanhóis se aventurarem por mares desconhecidos, a Europa já sonhava com paraísos terrestres. Sobre a mistificação européia dos trópicos, ver Augras, 1991; Buarque de Holanda, 2003 [1968]; Del Priore, 1992; Deleneau, 1992; Todorov, 1993; Turner, 1990 e Casalla, 2003. 
Sob a sombra de Carmen Miranda e do carnaval

revelia de outros. No caso da exotização européia da América, ou da exotização "americana" do Brasil, as características em torno das quais a fantasia se desenvolve sempre convergem para um primitivismo já superado pelas sociedades civilizadas ou completamente desenvolvidas do observador. Nesse sentido, exotização já não representa a preferência pela diferença, como a etimologia da palavra sugere, mas uma representação deformada que facilita e justifica a dominação. Ou seja, a relação entre exotizador e exotizado, tal como desenvolvida no mundo ocidental, é delimitada por uma outra, aquela entre colonizador e colonizado. É, portanto, "uma relação de dominação, não de reciprocidade" (Id. ib:315).

No contexto desses significados e relações, a integração imigrante ocorre em todos os lugares do mundo. Imigrantes - e forasteiros em geral - sempre têm de lidar com imagens sobre si, das quais, muitas vezes, eram completamente ignorantes antes da imigração. Em pesquisa de campo, desenvolvida em Los Angeles entre 1997 e 1999, observei que, além de aprenderem novas formas de lidar com as questões de classe, raça, nacionalidade, gênero e linguagem, as imigrantes brasileiras ainda tinham de lidar com a sua exotização e suas consequencias. Todas as brasileiras com quem conversei sobre o assunto eram conscientes do estereótipo. Algumas acreditavam que o estereótipo restringia seus movimentos, promovia a idéia de prostituição $e$, consequentemente, produzia um impacto negativo sobre as brasileiras, particularmente as que vivem fora. Outras, porém, consideravam que a imagem é vantajosamente ambígua e que depende de cada uma ratificar ou negar qualquer conexão com prostituição e submissão. O objetivo deste artigo é discutir as estratégias que as brasileiras imigrantes pertencentes às classes médias e médias altas utilizam para negociar imagens estereotipadas em seu favor. 


\section{A pesquisa e o contexto: brasileiros em Los Angeles}

O número de brasileiros na região metropolitana de Los Angeles é estimado em 33.000 (MRE, 2001). ${ }^{2}$ Embora relativamente pequena, essa comunidade tem tido grande importância na difusão da cultura brasileira no mundo. O grande exemplo é Carmen Miranda, que inspirou a indústria cinematográfica de Hollywood para criar e disseminar o estereótipo ainda dominante - embora bastante questionado - da mulher brasileira (e latina) (Beserra, 2003:42). A comunidade brasileira de Los Angeles também foi capaz de projetar a popularidade da música brasileira por todo o mundo através da indústria de gravações, assim como dos sofisticados serviços de marketing, distribuição e promoção (Riedinger, 1997).

Essa suposta conexão entre Los Angeles e a projeção internacional da cultura brasileira e o fato de que samba $e$ carnaval têm sido as formas mais importantes de difusão da cultura brasileira em Los Angeles, mas também em outras tantas cidades do mundo, me levaram a incluir no meu projeto de pesquisa o estudo das escolas de samba existentes na região. ${ }^{3}$

Além dos brasileiros ligados ao samba e ao carnaval, concentrei minha atenção em dois outros grupos. Entre 1997 e 1999, observei e participei dos encontros regulares e outras reuniões (festas de aniversário e casamento, chás de bebês, etc.) da Igreja Adventista de Fala Portuguesa de Chino e do Grupo das Brasileiras. Esses grupos foram escolhidos porque apresentavam modos distintos de integração dos brasileiros na região. Enquanto o primeiro representava uma experiência mais comunitária de integração, o segundo se aproximava mais da experiência mais individualista das elites. Nenhum dos grupos era homogêneo em

2 O Ministério das Relações Exteriores estima que 90\% da população imigrante brasileira nos Estados Unidos está concentrada na costa Leste (New York 300,000; Miami 200,000, and Boston 150,000).

3 Sobre escolas de samba e carnaval noutras cidades e países, ver Torresan, 1994; Ribeiro, 1997; Machado, 2004. 
Sob a sombra de Carmen Miranda e do carnaval

termos da posição social dos seus membros, entretanto, a experiência de cada um se aproximava mais das classes trabalhadoras ou elites, respectivamente. Outras características desses grupos também me atraíram: o primeiro apresentava uma possibilidade bastante particular de integração. Ao contrário da maioria da população brasileira, católica, os componentes do grupo foram, em geral, socializados como protestantes e sempre mantiveram laços próximos com os Estados Unidos em decorrência de o adventismo do sétimo dia ter nascido neste país. O segundo, como o próprio nome sugere, reúne apenas mulheres e se organiza em torno de questões de gênero e, inclusive, uma das suas missões é criar e difundir uma imagem de mulher brasileira separada do conteúdo erotizado da existente.

Durante o período da pesquisa, entrevistei longamente 15 membros de cada uma das associações e outros brasileiros ligados a instituições, como o Consulado do Brasil em Los Angeles, a Câmara de Comércio Brasil-Califórnia, o Comitê Sociocultural Brasileiro, o Centro Cultural Gaúcho, a Comunidade Evangélica Brasileira - Exército da Salvação, as escolas de samba MILA e SambaLA e os organizadores do carnaval do Hollywood Palladium.

Em conversas face a face ou pelo telefone, coletei dados socioeconômicos (idade, tempo de imigração, estado de nascimento no Brasil, grau de instrução, estado civil e emprego antes e depois da imigração) de 195 indivíduos, a maioria ligada aos dois grupos pesquisados.

A informação demográfica existente sobre a população brasileira nos Estados Unidos é bastante limitada. No período em que desenvolvi o estudo, o censo americano não produzia o perfil socioeconômico desta população e os estudiosos usavam suas amostras para criar tais perfis. O perfil construído a partir da minha amostra apresenta algumas diferenças em relação aos produzidos por estudiosos da população brasileira na costa 
leste. ${ }^{4}$ Dos 195 brasileiros sobre os quais coletei informações na área metropolitana de Los Angeles, 65\% eram mulheres, aproximadamente $40 \%$ casadas, divorciadas ou viúvas de americanos. A maioria dessa população é oriunda do Sudeste Rio de Janeiro (27\%) e São Paulo (20\%) -, mas também imigrantes do Rio Grande do Sul (14\%) e da Bahia (7\%). A maioria (76\%) imigrou para os Estados Unidos durante as duas últimas décadas, principalmente entre 1981 e 1999.

Em geral provenientes das classes médias, a maior parte da minha amostra frequentou a universidade $(52 \%)$ ou concluiu o ensino médio (32\%). Há uma relativa congruência entre o nível de instrução da população pesquisada e os empregos que possuem, especialmente entre aqueles que vivem há mais tempo na área.

Dos 174 brasileiros casados, viúvos ou divorciados da amostra, 113 (65\%) são do sexo feminino. Esta disparidade entre homens e mulheres foi produzida em função de, como expliquei acima, um dos grupos estudados ser composto apenas de mulheres. Provavelmente também por isto, a proporção de brasileiras casadas com americanos é maior se comparada à de brasileiros casados com americanas. Essa desproporção exagerada merece uma atenção especial. Dos mencionados 174 brasileiros, $110(63 \%)$ têm ou tiveram cônjuges brasileiros, 52 (30\%) têm ou tiveram cônjuges americanos e 12 (7\%) estão ou foram casados

\footnotetext{
${ }^{4}$ Margolis (1994:83-88), por exemplo, afirma que os brasileiros que viviam em New York no período da sua pesquisa eram quase igualmente divididos entre homens e mulheres, principalmente solteiros $(60 \%)$, jovens $(79 \%$ da amostra tinha menos de 40 anos) e que apresentavam alto índice de educação ( $46 \%$ tinham nível superior). Ela também observou que embora fossem todos bem educados, a maioria (aproximadamente 90\%) tinha empregos típicos de imigrantes. Ao longo da última década, outras pesquisas têm produzido outros perfis para a população imigrante brasileira nos Estados Unidos. Esses estudos concordam, porém, que os seus perfis não representam a realidade da população brasileira nas cidades estudadas, mas oferecem uma idéia da composição dessas populações. Para mais números e estatísticas sobre os brasileiros nos Estados Unidos, ver Goza, 1994; Margolis, 1994 e 1995; Sales, 1995; Davis, 1997; Ribeiro, 1997; Martes, 2000; DeBiaggi, 2002; Beserra, 2003.
} 
Sob a sombra de Carmen Miranda e do carnaval

com indivíduos de outras nacionalidades. Dos 52 brasileiros casados com americanos, $45(85,6 \%)$ são do sexo feminino $e$ somente $7(13,4 \%)$ do masculino.

\section{Conscientizando-se do estereótipo e das suas consequências}

Durante os cinco anos em que vivi em Riverside, Califórnia, entre 1995 e 2000, me familiarizei com uma versão de Brasil e brasileira que ignorava completamente antes de morar nos Estados Unidos. Foi uma revelação bastante interessante, a da atração dos americanos pelo Brasil: Brazil? Uau! Mas também era um pouco desagradável lidar com expressões exageradas ou limitadas desta atração: certo dia, o técnico da companhia de TV a cabo veio consertar a nossa antena. Após perceber o meu sotaque, ele (americano branco, entre 25 e 30 anos) me perguntou de onde eu era. Após ouvir minha resposta, ele me olhou bastante surpreso e afirmou: "Brasil?! Eu não sabia que havia brasileiros no sul da Califórnia!", e ficou meio paralisado me olhando como se eu fosse parte de alguma espécie em extinção. Após o choque, ele até se desculpou da reação exagerada e explicou que era a primeira vez que encontrava uma brasileira em carne e osso e me disse que alugava canais de TV que apresentam shows especiais com brasileiras. Não me senti encorajada a perguntar que tipo de show, porque já estava me sentindo desconfortável com toda a situação.

Muitas vezes, porém, ao contrário da situação acima, sentia como se a palavra Brazil tivesse o poder de fazer as pessoas sonharem acordadas. Em diversas circunstâncias, as mais variadas pessoas me contaram sobre os seus sonhos de visitar o Brasil. Suzana, uma amiga mexicana-americana me revelou que aprendeu a gostar do Brasil porque sua avó sempre falava do seu desejo de visitar o carnaval do Rio de Janeiro. Sua avó morreu sem realizar o sonho, mas ela me disse, "quem sabe se não sou eu quem deverei realizar por ela?". 
Aos poucos fui percebendo que, diferente do estereótipo do latino, que evoca padrões de imigração e estratificação social, o erotizado e tropicalizado estereótipo de brasileiro/a parecia mais flexível e também mais emancipatório. ${ }^{5}$

Minha primeira "professora" de políticas coloniais e neocoloniais de classificação foi Amélia, uma estudante brasileira que encontrei logo que cheguei em Riverside. Consciente dos jogos de poder envolvidos na produção da mulher latina como primitiva, submissa, sensual, desejável e promíscua, Amélia, entretanto, meio paradoxalmente, sempre se fantasiava da mesma boneca baiana que ela veementemente criticava.

Como Amélia, logo aprendi que a reação entusiasmada $e$ positiva ao vocábulo Brazil se baseia principalmente nas fantasias desenvolvidas em torno do carnaval, mas este incômodo, nunca me levou a mentir sobre a minha nacionalidade, como é o caso de Elizabeth, 67 anos, casada com um americano branco e morando em Los Angeles desde 1985:

De um modo geral a idéia que os americanos têm do Brasil é carnaval. Carnaval e as mulheres mais bonitas do mundo! Carnaval quer dizer tá sempre pronto pra farra. Quer dizer, dizer que é brasileiro já é dar um sinal verde. É um convite à molecagem. A maior propaganda do Brasil é uma bunda... se tivesse um outdoor do Brasil seria uma bunda enorme. Agora, me diga, por que é que o Brasil tem que ser representado por bundas a vida inteira? Se não é apenas uma bunda, são trinta. $\mathrm{O}$ anúncio do carnaval do Hollywood Palladium era uma coisa horrorosa, não sei quantas bundas de mulata. Até quando o Brasil vai viver de bunda? Pois é, é esse o mercado que se oferece pro Brasil aqui: bunda, sexualidade, carnaval. Quer dizer, não é nada sério. Muitas vezes eu até digo que sou portuguesa. Quando estou num meio mais sério, nem tenho coragem

${ }^{5}$ Em outros artigos (Beserra 2000b, 2005a e 2005b) discuto em detalhes a relação entre brasileiros e outros "latinos" nos Estados Unidos. Ver também Martes, 2003 e Tosta, 2004. 
Sob a sombra de Carmen Miranda e do carnaval

de dizer que sou do Brasil por causa dessa reputação. Todo mundo olha pra minha cara e vê uma bunda. Eu não agüento mais essa quantidade de bundas que vêm junto com a idéia de Brasil, não é possível! Parece um pesadelo! Então é assim, em todo canto, se não tiver umas trinta bundas de mulatas, de preferência, parece que não passa a mensagem, não vende. Até o consulado brasileiro promove isto.

O trecho de entrevista revela que a construção de identidades em terras estrangeiras pode tornar-se um empreendimento bastante dramático quando a imagem do grupo ao qual se pertence é um composto de características com as quais o indivíduo não se identifica. Não apenas no caso do Brasil ou de países colonizados, mas, em geral, as imagens através das quais populações e países são representados são quase impossíveis de se identificar porque são sempre muito abrangentes e superficiais para caber qualquer indivíduo concreto. ${ }^{6} \mathrm{O}$ que Elizabeth sugere acima é que não há espaço para reivindicar sua identidade brasileira, porque esta é muito carregada de significados com os quais ela não está disposta a lidar. Mais: ela se sente sem poder para transformá-los, porque "até o Consulado Brasileiro promove isto". Ou seja, que poder tem ela para questionar uma versão de Brasil divulgada pelo próprio Consulado do Brasil? Se tal imagem fosse apenas uma construção exótica produzida pelo outro longínquo, americano ou europeu, ela poderia mais facilmente

\footnotetext{
6 Situação semelhante, embora com consequências opostas, é a do estereótipo do homem ocidental que enfatiza suas qualidades ou as qualidades do homem dominante. Estudando exotização de asiáticas, Prasso afirma: "nos bares de Bagkok e noutras partes da Ásia, os homens ocidentais vêem restituídas as noções tradicionais de masculinidade bastante diminuídas pelas expectativas das culturas modernas. Na percepção que têm da sua interação com as mulheres e a cultura asiáticas, eles experimentam sentimentos de superioridade, riqueza, poder e masculinidade, ao menos temporariamente. Aqui qualquer homem pode experimentar o sentimento de se tornar novamente atraente e até amado. Velhos, gordos ou feios - pelos padrões ocidentais, não importa. Qualquer um pode ser o Alpha Male ou o Lord Jim" (Prasso, 2005:7).
} 
questioná-la. Porém, seus argumentos perdem consideravelmente a força quando é o próprio governo brasileiro que reforça o exotismo. Assim, ao invés de uma referência positiva, sua ligação com o Brasil funciona como uma armadilha que ela tenta evitar sempre que tem a possibilidade de passar por portuguesa. ${ }^{7}$ Seu comentário revela, entre outras coisas, como já salientei, a dificuldade de integração quando o grupo imigrante ao qual o indivíduo pertence é representado de uma forma que tão claramente interfere na sua vida. Mas demonstra também considerando que muitos brasileiros, inclusive a própria Diplomacia, promovem essa imagem polêmica - que a variedade de versões de um povo é o resultado da diversidade de visões de mundo de classes sociais e outros grupos numa sociedade historicamente determinada. As características selecionadas para compor essas imagens são escolhidas ou definidas em função de interesses circunstanciais dos grupos hegemônicos e geralmente têm propósitos historicamente definidos em cada nova configuração de poder (Larrain, 1994). No caso específico da imagem da brasileira exótica, feliz, dócil, ou do brasileiro cordial, é importante chamar a atenção para os diversos modos como as interpretações do Brasil, produzidas pelos próprios brasileiros, são apropriadas e resignificadas num contexto internacional. ${ }^{8}$

Dois aspectos fundamentais precisam ser considerados na investigação da construção de identidades imigrantes: um se

\footnotetext{
7 É interessante observar que ela considera mais simples se passar por portuguesa do que apresentar, com o seu comportamento diferente do estereótipo, outro significado para brasileira. Neste caso, identificar-se como portuguesa também a livra do lugar de terceiro mundo e seus estigmas. A questão que permanece é: como lidam com o estereótipo as brasileiras que o recusam e não podem passar por portuguesas, russas, francesas ou outras nacionalidades européias?

${ }^{8}$ No artigo "Before We Called This Place Home: Precursors of the Brazilians Community in the United States", Darien Davis (2005) mostra como os artistas brasileiros imigrantes ou visitantes ocasionais colaboraram na construção da imagem estereotipada de Brasil divulgada por Hollywood e pela mídia americana.
} 
Sob a sombra de Carmen Miranda e do carnaval

relaciona à dinâmica da política doméstica nos países de origem $e$ destino e o outro à importância dos países, no caso Brasil e Estados Unidos, no panorama político internacional (Beserra, 2000a e 2003).

O surgimento do nacionalismo se dá num mundo já globalizado pelo modo de produção capitalista, motivo pelo qual as identidades nacionais são forjadas no contexto de submissão e/ou resistência à expansão do regime colonial. Anderson (1991:53) explica que o nacionalismo precoce na América Latina foi também resultante da forma como a Europa tratava seus filhos mestiços. Os europeus acreditavam que os índios e os negros haviam contaminado seus descendentes e assim estes deveriam ser tratados. A discriminação européia contra seus "descendentes" que compartilhavam a fatalidade de um nascimento transatlântico fê-los aproximar-se de índios e negros e olhá-los como parte de uma nova e diferente comunidade cujo objetivo mais importante era se libertar do domínio e exploração europeus.

O Brasil compartilha com a maioria das nações o destino de ter sido criado sob o controle de poderes coloniais. A identidade nacional brasileira, portanto, será construída a partir da relação com o outro dominante, mas também dos embates e encontros internos. Estes embates e encontros, de acordo com vários intérpretes do Brasil, elevaram o samba, o carnaval e o futebol à categoria de símbolos nacionais. ${ }^{9}$

Apesar do poder efetivamente conferido a cada um dos grupos étnicos e raciais participantes da identidade, os elementos culturais escolhidos para representar o país são vinculados à mistura entre os grupos. É possível argumentar que esses elementos culturais são apenas alguns dentre vários que poderiam ter sido escolhidos, mas o fato é que foram estes que, na circunstância em que o Brasil precisava se tornar uma nação, foram elevados à categoria de símbolos nacionais e difundidos

9 Ver, entre outros, Da Matta, 1984; Menezes, 1992; Ortiz, 1991; Ribeiro, 1995; Vianna, 1999; Franzini, 2000 e McCann, 2004. 
pelo país inteiro. Dessa forma, é difícil imaginar que outros símbolos representariam tão adequadamente o Brasil, uma vez que todos acabamos por nos acostumar a reconhecê-los como parte da alma nacional. ${ }^{10}$

Independentemente de quanto o Brasil se transformou dos idos de 1930 para cá, as imagens veiculadas no mundo continuam muito próximas das criadas e difundidas então. Mesmo que houvesse um consenso sobre o que é hoje o Brasil e que símbolos culturais o representariam mais adequadamente, sua posição no jogo internacional de poderes limitaria bastante as possibilidades efetivas de criação de novas imagens ou transformação das existentes.

No caso dos brasileiros em Los Angeles, entretanto, há a possibilidade de se optar entre exotização e latinização, como explica Ivan Becker, 44 anos, jornalista,

O brasileiro, talvez fruto da sua própria ignorância, é aquilo que ele é. E a gente, com todos os nossos defeitos, não tem uma atitude submissa perante ninguém. $\mathrm{O}$ brasileiro médio, o brasileiro simples não se acha menos do que ninguém. Ele acha que é brasileiro. E quando chega nas áreas que ele é bom, então ninguém chega perto! Seja no futebol, samba, música, sexo, naquelas coisas que a gente acredita que é bom, na imagem positiva da gente. E o brasileiro, o que é que a gente acredita que é o brasileiro? A gente acredita que todo brasileiro é bom de bola, todo brasileiro é bom de papo, todo brasileiro é bom de sexo, de música, de festa. Nós é o quente! Nós é os quindin de iaiá. E as imagens que o mundo tem do Brasil é de bom de bola, bom de samba, bom de foda, bom de tudo, entende? E exótico! No fundo

\footnotetext{
${ }^{10}$ Para uma visão da identidade nacional brasileira em relação aos elementos incluídos ou excluídos da sua composição, e da perspectiva de um brasileiro do Rio Grande do Sul, estado que não se enquadra no estereótipo tropical, ver Ruben Oliven (1996). Para a compreensão da negociação da identidade brasileira entre brasileiros nos Estados Unidos, ver Ribeiro, 1997 e 1998; Sales, 1999, Beserra, 1998, 2003 e 2005 e De Lourenço, 2004.
} 
Sob a sombra de Carmen Miranda e do carnaval

eles gostam porque eles não conhecem muito, eles não sabem muito a respeito. Então a gente não é colocado no mesmo barco... Sabe? Num país racista como este, o brasileiro até tem uma posição privilegiada porque a gente não é colocado junto com os outros latinos, brasileiro é uma categoria à parte.

Se as circunstâncias requerem que os brasileiros se identifiquem com a imagem de latino ou com a imagem brasileira exotizada, é muito provável que eles escolham esta em função das razões apresentadas acima, mas principalmente da última, isto é, o Brasil está bastante distante para permitir que os americanos confiram a veracidade das imagens. Desse modo, a imagem exótica é mais flexível que aquela que o termo latino geralmente evoca em Los Angeles: padrões de imigração e estratificação social. Neste caso, a exotização de brasileiros, contestada em várias outras circunstâncias, é vista como positiva, uma vez que relativiza sua inclusão entre os latinos que competem com os negros pelo lugar de mais discriminados nos Estados Unidos (Oboler, 1992; Beserra, 2003 e 2005; Kearney e Beserra, 2004).

Mas aceitar uma imagem estereotipada é, de certo modo, se submeter à idéia de permanecer uma criação do colonizador e limitar os movimentos às fronteiras restritas da sua imaginação. Que fazer então? As agências governamentais brasileiras, assim como os brasileiros imigrantes, não parecem ter muita escolha, a não ser aceitar, ao menos temporariamente, a imagem internacional do Brasil $e$ negociar as suas consequências individualmente. ${ }^{11}$

${ }^{11}$ Recentemente, em conversa com um diplomata brasileiro em serviço no Oriente Médio, perguntei se as imagens de Brasil apresentadas aos muçulmanos são as mesmas divulgadas nos Estados Unidos e na Europa. Ele argumentou que o Governo Brasileiro não pode fazer nada, a não ser iniciar a partir do que já existe. Assim, ao invés de questionar estereótipos universais do Brasil, ele os usa para atrair a atenção de outros povos sobre a cultura brasileira. Uma vez mais próximos do Brasil e dos brasileiros, acha mais provável que possam questionar os estereótipos e mudar sua percepção. Ele admite que a única forma de 
Independentemente da possibilidade de negociar essas imagens em seu favor, muitos brasileiros se sentem mal representados pela redução do Brasil a três ou quatro imagens. Gustavo Ribeiro (1997:7), em estudo sobre os brasileiros em San Francisco, expressa seu mal estar:

é um pouco desconfortável para um antropólogo desenvolvendo pesquisa sobre os seus conterrâneos em outros países descobrir que, no final, a identidade nacional brasileira é reduzida às suas expressões mais estereotipadas: carnaval, feijoada, capoeira, samba, futebol e, não menos, aos biquinis fio-dental.

Senti algo semelhante quando estava estudando os brasileiros em Los Angeles. Lembro-me ainda de quão desconfortável me sentia quando comecei a frequentar bares, restaurantes e clubes brasileiros. Sempre tinha a impressão que o Brasil estava sendo grosseiramente mal representado. Afinal, como podia um país tão "grande e rico" como o (meu) Brasil ser reduzido a três ou quatro imagens exóticas?" (Beserra, 2003:5).

Apesar de todas as nações serem também reduzidas a três ou quatro imagens, é importante observar que sua produção é sempre condicionada pela base racista da expansão imperialista/colonialista. Somente as nações e povos da Europa ocidental (e seus descendentes "puros"), os Estados Unidos e o Canadá possuem os atributos para classificar e exotizar o mundo inteiro. Apenas eles "têm o poder de transformar seus discursos sobre o outro numa verdade universal" (Savigliano 1995:9). Portanto, além da questão filosófica entre nós e eles, a exotização sempre tem tido propósitos bastante práticos. Ela funciona, por exemplo, como uma manobra do colonizador para manter o colonizado no seu lugar. Primitivo, selvagem, amoral e assim por

compreender/interpretar o Brasil num contexto internacional é relacionando-o às idéias já existentes no mercado, o que sugere que somente temos a opção de negociar a imagem estereotipada. 
Sob a sombra de Carmen Miranda e do carnaval

diante, o exotizado é sempre posto numa posição que demanda a intervenção, ajuda ou dominação do civilizado (Aparicio \& Chávez-Silverman, 1997; Benz, 1997; Urraca, 1997). Mas a exotização também funciona como uma forma de mercantilizar o colonizado e seus "bens", sejam estes quais forem. Música, dança, sexo e comida transformam-se em mercadorias submetidas a regras semelhantes às que regulam outros produtos no mercado capitalista. E o mesmo acontece com as pessoas.

Em estudo desenvolvido sobre brasileiros imigrantes em Portugal, Machado (2004) observa que, uma vez se enquadrando na imagem de brasileiro cultivada naquele país - que não é particularmente diferente da existente nos Estados Unidos -, esses imigrantes adquirem mais valor num mercado que funciona baseado na vantagem estrutural dos brasileiros (exóticos) sobre outras nacionalidades. Neste caso particular, os que são mais brasileiros são melhor recompensados. Em consequência, logo têm que enfrentar o desafio de se transformarem em verdadeiros brasileiros, o que significa, entre outras coisas, dançar samba, fazer feijoada, jogar futebol, "ser feliz" e assim por diante. Desse modo, trabalham deliberadamente na produção da própria exotização $e$ se transformam no que Machado (2004:218) chama de "vítimas e agentes de uma subordinação ativa". Assim, são vítimas em relação ao fato de que não têm poder para mudar (às vezes nem mesmo questionar) a imagem do Brasil $e$ dos brasileiros internacionalmente, mas são agentes no sentido de que não contestando a imagem dominante e negociando-a obtêm vantagens sobre os que são menos brasileiros ou não brasileiros: transformam-se nos autênticos representantes do Brasil e da brasilidade.

A opinião de Elizabeth também chama a atenção para o fato de que a masculinidade do colonizador tende a produzir a exotização em torno da mulher e, complementarmente, da efeminação do homem colonizado, defendem alguns estudiosos (Memmi, 1991; Fanon, 1963 e 1967 e Sinhá, 1995). Ou seja, com o propósito de enfatizar o poder e a necessidade da intervenção do 
colonizador, os homens colonizados são quase sempre retirados de cena ou efeminados. A exotização do Brasil, como observada por Elizabeth, está fortemente concentrada na exotização da brasileira, motivo pelo qual ela sugere que somos nós que suportamos sozinhas este fardo. ${ }^{12}$

Defendo a idéia de que as brasileiras tornaram-se uma mercadoria no mercado do exotismo cultural e sexual desde que Hollywood usou Carmen Miranda para difundir o mito da sensualidade e graça da mulher brasileira, posteriormente alimentado pela transmissão do carnaval, especialmente o desfile das escolas de samba do Rio de Janeiro. Os velhos mitos do paraíso tropical provavelmente inspiraram e guiaram a criação de novos mitos, agora produzidos também pelos próprios brasileiros para alimentar as indústrias cultural e turística. A diferença entre hoje e a Europa do século XVII é que naqueles tempos a exotização era uma criação estrangeira baseada na distância e na ignorância. Hoje, ela é recriada com o apoio e conhecimento dos próprios brasileiros. Assim, os colonizadores distantes, europeus ou americanos, não são mais os únicos a se beneficiar do

\footnotetext{
${ }^{12}$ Analisando os escritos de Pierre Loti, Todorov (1993:308-323) observa que o oficial naval e escritor francês reduz os países que visita às suas mulheres. Assim, ao invés de uma relação colonial, ele mostra uma "relação estritamente individual: "esta relação dual, de um homem com uma mulher e um europeu com uma estrangeira não é de forma alguma simétrica e nem poderia ser: uma experiência devotada à busca de impressões implica [...] que o viajante é o único ser humano elevado à categoria de sujeito; as mulheres são apenas o objeto mais saliente da sua percepção. O viajante masculino é ativo; chega num dia e no dia seguinte vai embora. Entre esses dois eventos aprendemos sobre suas experiências e sensações. A mulher e o país estrangeiro (a mulher porque é uma estrangeira e o país porque é erotizado) se permitem ser desejados, governados e abandonados" (Id. ib.:315). Todorov insiste na posição de sujeito ativo do viajante europeu e conclui que "as duas fases da relação - a atração pelo incompreensível estrangeiro e o abandono final - traduz perfeitamente a ambivalência do exotismo de Lotti. O macho europeu é atraído e seduzido, mas ele invariavelmente volta para a terra de onde veio. Ele ganha em dois sentidos: tem o benefício da experiência exótica (uma mulher e um país estrangeiros) sem precisar questionar seu pertencimento ou sua identidade" (Id. ib.: 328).
} 
Sob a sombra de Carmen Miranda e do carnaval

fenômeno da exotização. Quem são os brasileiros que alimentam essas imagens ou, nos termos de Machado, quem são os agentes e vítimas da exotização?

O discurso de Elizabeth sugere que as indústrias cultural $e$ turística são os agentes $e$ beneficiários $e$ as mulheres são as vítimas. Mas o fenômeno é mais complicado, de acordo com o que veremos na próxima seção deste artigo. Por enquanto, apesar da sugestão de Elizabeth, continuarei sustentando a hipótese de que, no geral, os brasileiros tornam-se simultaneamente agentes e vítimas da construção da imagem tropicalizada da brasileira.

Hollywood transformou Carmen Miranda num ícone da mulher tropical: sexy, simpática, submissa e assim por diante. Tal imagem não foi imediatamente aceita e reforçada pelos brasileiros. De fato, a personagem foi bastante contestada por vários grupos da sociedade nacional e, inclusive, acusada por setores da mídia brasileira de não representar o Brasil adequadamente. Carmen Miranda tentou explicar que sua representação podia até ser americanizada, mas ela continuava bastante brasileira. Até inspirou a canção Disseram que eu voltei Americanizada, na qual argumenta que apesar das aparências continuava bastante brasileira. A questão, no entanto, não era esta. Que importância teria guardar sua brasilidade para si própria? O problema era, de fato, o da sua submissão em incorporar uma versão tão limitada da mulher e cultura brasileiras. A Folha da Noite, jornal de São Paulo, registrou sua reprovação nos seguintes termos:

então é assim que o Brasil brilha nos Estados Unidos: com uma portuguesa cantando sambas negros de mau gosto. É exatamente assim e é assim que deve ser porque não há realmente muita gente neste país que valha tanto quanto esta Carmen, a grande e excelente Carmen, que saiu daqui para cantar essas besteiras lá fora (Davis 1997:13).

A imagem da mulher brasileira, materializada através de Carmen Miranda, desenvolveu-se e sofisticou-se com a 
transmissão do desfile de escolas de samba do Rio de Janeiro para o mundo. Inclusive, a imagem de mulher brasileira que Elizabeth questiona não é a da baiana, criação de Carmen Miranda, mas aquela mais sexualizada promovida pelo carnaval. ${ }^{13}$

Entretanto, relacionar a imagem da mulher brasileira produzida pelo carnaval a sexo e prostituição exclusivamente é uma simplificação do que efetivamente ocorre. De fato, sexo e prostituição são apenas dois entre vários outros subprodutos do carnaval brasileiro. Entrevistando americanos e outros não-brasileiros no carnaval de 1999 do Hollywood Palladium, em Los Angeles, fui forçada a repensar a idéia predominante de sexualidade relacionada ao carnaval brasileiro. Um dos entrevistados, um americano branco, mais ou menos 40 anos, disse-me que relaciona carnaval com música, dança, festividade $e$ sensualidade:

para mim tudo é muito sexual, mas sexual de uma forma muito especial. É a celebração do corpo com música e alegria. É uma forma bastante positiva de trazer a sexualidade à cena pública. Tudo: música, liberdade, fantasias... conduz a uma forma bastante especial de celebrar o corpo.

Mais do que a conexão de carnaval com sexo, ele inclui na sua percepção a magia e a poesia ligadas à idéia geral de carnaval para finalmente chegar à sexualidade fantasiada, livre do fardo da repressão protestante.

${ }^{13}$ Usar o carnaval como a fonte principal da representação internacional do Brasil é, particularmente, problemático e restrito, porque significa produzir uma representação a partir de outra. Além disso, carnaval é um tipo bastante especial de representação. Primeiro, o carnaval acontece num tempo e espaço particulares. Segundo, como um ritual de inversão, os símbolos e comportamentos do carnaval não refletem a realidade como ela é, mas como os brasileiros a representam para os propósitos do evento. Terceiro, embora o carnaval das escolas de samba tenha se tornado a referência internacional de carnaval brasileiro, ele é apenas uma entre as várias versões existentes no país. 
Sob a sombra de Carmen Miranda e do carnaval

\section{Negociando imagens: de Carmen Miranda a Gisele Bündchen}

Sexy, bonitas, animadas, alegres, inocentes, submissas e promíscuas: como as brasileiras imigrantes em Los Angeles lidam com essas imagens? ${ }^{14}$

Ouvi várias histórias das brasileiras com quem conversei sobre o assunto. Uma amiga jornalista me contou que uma convidada sua, classe média alta, em visita a Los Angeles, percebeu a reação especial de um americano branco a quem foi apresentada: "Ah, Brazil?!..." Ao ouvir isto, ela comentou com a minha amiga, em português, "por que este senhor está tão animado em saber que sou brasileira? Será que ele acha que somos todas putas?"

Porém, nem todas as imigrantes brasileiras reagem tão defensivamente à manifestação do estereótipo. Paola, 35 anos, professora universitária, explica:

Eu não me incomodo de jeito nenhum com os americanos se aproveitarem do fato de eu ser brasileira pra sonharem um pouco com uma sensualidade que eles não têm, coitados. Eles olham pra mim como se eu guardasse algum segredo que eles dariam tudo pra descobrir. Eu alimento um pouco o estereótipo, claro. Acho que no fundo também acredito nele.

Paola, como Gisele Bündchen, não é o melhor exemplo da propagandeada mestiçagem brasileira. De fato, ela se enquadra mais facilmente no estereótipo da americana branca que da brasileira mestiça. Sua explicação sobre como ela lida com o estereótipo da brasileira sugere duas interpretações: ser brasileira, no seu caso, apenas apimenta um pouco sua vida. Segundo, ela

\footnotetext{
${ }^{14} \mathrm{~A}$ ironia e o senso de humor também faziam parte dos atributos da brasileira/latina criada por Carmen Miranda, mas estes não se tornaram tão populares quantos os outros, menos desafiadores do ponto de vista do conquistador/exotizador.
} 
está convencida de que realmente há uma forte correspondência entre o estereótipo e a realidade: "no fundo, eu acho que eu também acredito nisto". De fato, é uma crença compartilhada tanto pelo exotizador como pelo exotizado. Estando constantemente sob o olhar do exotizador, o exotizado acaba por incorporar a sua verdade. Mas as coisas não são tão simples $e$ mágicas como Paola descreve. Em outras conversas, ela se referiu diversas vezes ao quanto tem que trabalhar para conquistar o mesmo respeito e recompensas que seus colegas. Sua queixa, no entanto, parece bastante similar às das feministas em geral: quando competindo em áreas tradicionalmente masculinas, as mulheres têm que trabalhar muito mais porque os homens estão sempre suspeitando que elas podem recorrer a estratégias não ortodoxas. Em relação a seu trabalho, ela declara que tem tido problemas tanto com seus colegas como com as suas esposas. Eles acreditam mais na eficiência da sua beleza do que na sua inteligência e disciplina. Contudo, no final, além de se provar tão capaz quanto seus colegas, ela parece ter a vantagem adicional do sex appeal brasileiro, que pode usar eventualmente como um trunfo para negociar favoravelmente sua posição de imigrante em Los Angeles.

Para Annie, 36 anos, essas negociações parecem mais complicadas, como aparece em seu diálogo com o marido, Ivan, 44 anos, jornalista:

I - Eu sei que o americano tem a maior fascinação pelas mulheres brasileiras. A fantasia coletiva deles é que as mulheres no Brasil andam todas de topless. Ninguém vai à praia no Brasil de topless, é muito raro, mas eles têm essa idéia. Eles acham também que é a maior sacanagem e tudo é festa. Mas é uma imagem positiva a que eles têm da gente.

A - Não, mas eu acho que essa idéia de que a mulher é quente, $e$ isso e aquilo, faz com que a imagem seja truncada à beça. Quando você diz que é brasileira, os outros latinos olham com uma fascinação: Uau! E os 
Sob a sombra de Carmen Miranda e do carnaval

americanos também. Mas eu acho que é uma imagem irreal, ruim pra gente. Não tem me atrapalhado muito porque tenho uma atitude muito séria, não sou uma pessoa que dá abertura pra esse tipo de coisa. E quando vejo que alguém vai falar alguma coisa, que vem com alguma idéia truncada, fecho o tempo. Eu não deixo ninguém entrar nesse departamento comigo não. Não dou abertura. Eu não tenho esse problema, normalmente. Mas eu tenho amigas que passam por isto. Por exemplo, fica muito mais fácil a paquera e os convites, sabe como é que é? Apesar de tudo, já fui cantada. De vez em quando eu ouço alguma coisa. Quando me perguntam de onde sou e eu falo, eu sou brasileira, as pessoas às vezes chegam perto $e$ aparentemente sem pretensão, começam... Ah brasileira, ah país do carnaval, aí começa. Depois do carnaval vem perguntar se você é casada e tal.

I - Ah, mas isto tudo porque você é bonita, eu tenho certeza que se você fosse uma mocréia ia pouco importar se você era da Transilvânia ou de Bruxelas.

A - Pois é, mas eu acho que quando eles sabem que a gente é brasileira, eles ficam mais incentivados.

I - Mas é porque esse negócio de sexo aqui é muito pesado. Do jeito que a gente faz no Brasil encanta eles porque a gente consegue lidar com o corpo e a sensualidade sem ser um bicho de sete cabeças. As mulheres andam de biquini nas ruas, mas ninguém está pensando em sexo o tempo todo. Os americanos ficam doidos porque eles não sabem lidar com o corpo com tanta generosidade, e pra eles tem que ser sempre com um segundo sentido. O brasileiro usa o corpo como mais um espaço de expressão da personalidade... Ela não precisa tirar a roupa pra conseguir um namorado, ela vai conseguir o namorado de qualquer maneira. Ela quer mostrar o corpo porque o corpo é dela e acabou! Eles ficam estonteados com isto, porque eles são tão mesquinhos em relação ao corpo e a gente tem tanta riqueza na expressão desse corpo, né? 
Annie e Ivan apresentam perspectivas diversas sobre o mesmo assunto. Ela insiste no seu desconforto com os sinais que recebe dos homens quando eles descobrem que ela é brasileira. Embora Ivan argumente que ela atrai a atenção dos homens porque é bonita, Annie insiste que a sua conexão com o Brasil é o que incita a atração masculina. E, claro, se beleza e atração sexual são as mercadorias à venda, é óbvio que o fato de ser brasileira adiciona um valor especial. Entretanto, se isto não está em jogo, é realmente irritante e desconfortável lidar com o que Annie chama "imagem truncada" da brasileira em Los Angeles.

Como Elizabeth, Annie insiste que a imagem conduz diretamente a sexo e permissividade. Ivan, no entanto, enxerga outros significados e relações, semelhantes aos que me foram apresentados no carnaval do Hollywood Palladium em Los Angeles, os quais sugerem que a fascinação que as brasileiras exercem sobre americanos não se relaciona apenas a sexo, mas também a fantasias exóticas.

A percepção de Ivan e Paola, de acordo com a qual os brasileiros têm uma forma bastante particular de lidar com a sexualidade parece ser compartilhada por muitos. Num artigo intitulado Pleasure Principle [Princípio do Prazer], publicado na Brazzil (revista em inglês para brasileiros imigrantes e outros interessados no Brasil), Espinosa (1997:13) afirma que:

O Club Med - uma cadeia de mais de 120 resorts de prazer espalhados pelo mundo - queria saber dos seus anuais 1.5 milhões de visitantes ricos qual o povo mais sensual da terra. Os homens e mulheres brasileiros foram votados como os mais quentes de todos.

O interessante na discussão desse tema é que, independentemente de como as brasileiras interpretam e lidam com o estereótipo, a maioria delas realmente acredita que as brasileiras são mais atraentes e sensuais do que as americanas, como apontam algumas entrevistadas: 
Sob a sombra de Carmen Miranda e do carnaval

Eu acho que é supernatural que os americanos se sintam atraídos pela idéia de brasileira que é distribuída aqui. Claro, são mulheres lindíssimas, com corpos maravilhosos, fantástico! E eles acham que o Brasil tem uma sensualidade que eles não têm, e eu sinceramente acho que eles estão certos em relação a isto. De fato, a mulher brasileira é muito sensual especialmente quando comparada com a americana! Qualquer uma de nós aqui tem mais sensualidade do que qualquer americana. Eu sei disto, todo mundo sabe disto. Não é só americano que sabe disto, entendeu? A minha questão é que a gente tem muito mais do que corpo bonito e sensualidade, entendeu? (Cláudia, 43 anos, morena clara).

É vantagem para a mulher brasileira casar com americano, agora, é desvantagem para o brasileiro casar com uma americana. Eu explico. O americano não está acostumado com uma mulher caseira, carinhosa, okay? E o brasileiro tá. E a americana não é caseira, não é carinhosa, não é feminina, e dizem que elas são ruins de cama. Eu conheço um brasileiro que casou com uma americana $e$ foi ele mesmo que falou pra mim. Mas ele casou mais pra ficar aqui no país. Mas ele viveu com ela, saía com ela pra tudo quanto era lado e apresentava ela como esposa. Mas ele diz que as americanas que ele conheceu deixavam muito a desejar sexualmente. Eu acho que elas começam o sexo muito cedo aí ficam muito máquina. Você entende? Não tem a sensualidade, o carisma e o jogo de cintura que nós, brasileiras, temos (Telma, 45 anos, morena escura).

Sejam quais forem as verdades parciais que a exotização espalha, elas são sempre compartilhadas pelos exotizadores $e$ exotizados. ${ }^{15} \mathrm{O}$ que é inicialmente uma verdade da perspectiva

\footnotetext{
${ }^{15}$ Os depoimentos acima também permitem observar que a distância e o desconhecimento alimentam a produção de estereótipos independentemente do lugar em que se situam os produtores/criadores. A diferença entre os estereótipos produzidos pelas brasileiras (sobre a frieza ou não feminilidade das americanas) ou quaisquer outros grupos não-hegemônicos e os hegemônicos, como
} 
limitada do outro, aos poucos, torna-se uma verdade para todos e tal verdade pode ser transformada num trunfo, dependendo do que está em jogo. Para aqueles que negociam prazeres sexuais de última geração, não há dúvidas sobre o valor da brasilidade exotizada.

Os trechos de entrevistas discutidos até aqui sugerem que os negociantes de "prazeres sexuais" não são os únicos beneficiários da brasilidade erotizada. Muitos brasileiros entrevistados discordam da interpretação de Elizabeth, na qual as mulheres são vítimas $e$ as indústrias cultural $e$ de turismo seus agentes $e$ beneficiários. Telma, por exemplo, não questiona a veracidade da reputação da sensualidade da mulher brasileira. Para ela, os atributos do estereótipo são parte dos seus atributos. Cláudia, por outro lado (como o diplomata que mencionei no rodapé 11), não está tão preocupada com o estereótipo, mas em ir além dele para mostrar ao mundo que as brasileiras são muito mais do que apenas beleza e sensualidade.

O comum nesses discursos é que o estereótipo é positivo, porque atrai pessoas ao Brasil e aos brasileiros, mas também porque é baseado na realidade. De fato, as brasileiras (e os brasileiros, de acordo com o Club Med) são os mais quentes, sexy e sensuais do mundo. Mas qual a importância de tais atributos quando o que está em jogo é arranjar um marido, um emprego ou a estabilidade na carreira acadêmica? Muitas brasileiras acreditam que mesmo no caso daquelas que procuram marido, não apenas sexo casual ou comercial, a imagem erotizada as afeta positivamente.

Meu marido tinha essa fixação por mulher negra. Ele tinha tido um relacionamento com uma americana negra de quem ele gostou muito, mas era um relacionamento muito complicado. Ele também se sentia muito atraído pelo Brasil $e$ todas aquelas fantasias relacionadas com carnaval $e$

assinalada anteriormente, é o poder que estes têm de tornarem universais os estereótipos que criam 
Sob a sombra de Carmen Miranda e do carnaval

mulatas. Eu acho que ele estava procurando essa mulata brasileira quando ele me encontrou (Jociclênia, 42 anos). ${ }^{16}$

Pelas suas conexões com colonialismo e dominação, é razoável supor que a atração pela brasileira leva mais "naturalmente" ao sexo casual que ao casamento uma vez que o exotizador, ativo, "sempre termina a relação com a mulher exotizada e invariavelmente volta para o lugar de onde veio" (Todorov, 1993:315). Aproximar-se do outro, no entanto, é um risco, porque cria a possibilidade de resultados inesperados. ${ }^{17} \mathrm{~A}$ proximidade, embora por um período curto, pode dissipar sonhos e fantasias, mas pode também aprofundar desejos, desprezo ou admiração pelas qualidades reveladas pelo exotizado, como propõe Marta, 45 anos, branca:

Não sei, sou casada com um brasileiro, mas acho que muitos estrangeiros alimentam esta crença de que as brasileiras podem oferecer os mais extraordinários prazeres sexuais, o sexo mais selvagem, o mais bonito... Mas eu não acho que esta é a única razão por que os americanos escolhem esposas brasileiras. Eu acho que eles também acreditam que a brasileira é mais submissa e tradicional que

\footnotetext{
${ }^{16}$ Embora no imaginário nacional brasileiro samba e mulata tenham se tornado sinônimos, tal relação não existe no imaginário dos americanos. Nesse sentido, o atributo brasileira funciona independentemente da cor.

${ }^{17}$ Apesar da tendência a "se voltar para o lugar de onde se veio", casamento entre homens europeus e americanos e mulheres "exóticas" têm-se tornado cada vez mais comuns nas últimas décadas, após o questionamento mais sistemático do patriarcado e a interrupção e/ou diminuição da recompensa a papéis tradicionalmente masculinos. Por outro lado, a porcentagem de brasileiras casadas com americanos, assim como de americanos (principalmente brancos) casados com outros grupos "étnicos", revela que os americanos e europeus estão consideravelmente mais propensos a casar com mulheres exóticas do que homens de outras nacionalidades, particularmente homens do terceiro mundo, uma vez que o mercado internacional de casamentos segue as regras gerais do colonialismo que determinam que os colonizadores são superiores (têm mais valor) do que os colonizados.
} 
a americana, o que geralmente é verdade. Quer dizer, é muito mais do que apenas sexo e diversão, entende? $\mathrm{Ou}$ deveríamos acreditar que os missionários mormons casam com brasileiras buscando apenas prazeres sexuais radicais?

Os depoimentos aqui discutidos, o trabalho de campo $e$ minha própria experiência sugerem que o estereótipo de brasileira - tal como vivenciado pelas brasileiras de Los Angeles com quem conversei sobre o assunto - é bastante flexível. Como qualquer estereótipo, inicialmente limita os movimentos do exotizado, mas não eternamente Ou seja, ir além de imagens estereotipadas está também nas mãos do exotizado. Voltemos ao caso de Paola. Ao invés de aprisionada nos limites do estereótipo, ela parece brincar com ele. É um jogo onde ela, aparentemente, possui todos os trunfos. Seu depoimento sugere que os poderes que exotizam também tornam-se escravos da própria criação. Todavia, é importante ter claro que, na sua situação presente, o estereótipo não restringe seus movimentos como o faria se ela estivesse em posição mais vulnerável.

Não me aprofundei nesta questão durante a pesquisa de campo, mas sou levada a acreditar que a eficiência da exotização - especialmente no sentido de manter o outro no seu lugar - é consequência de fatores outros além da exotização propriamente dita. Quanto mais os indivíduos se enquadram no estereótipo, mais eficientemente ele funciona.

\section{Conclusão}

Ao longo deste artigo, discuti exotização ao nível individual/ comunitário das brasileiras em Los Angeles, e nacional/ internacional, das imagens soltas de Brasil e brasileiros no planeta. Por enquanto, concluo que, apesar de todas as limitações impostas pelo colonialismo, há espaço para mudanças nos níveis individual e nacional. Independente do poder das imagens produzidas sobre o Brasil e de quanto, efetivamente, elas limitam 
Sob a sombra de Carmen Miranda e do carnaval

os movimentos do exotizado, tornar-se ou permanecer uma marionete nas mãos do colonizador/exotizador é uma escolha.

Paola, Cláudia, Marta e outras tantas brasileiras acreditam que além de sermos boas em relação às qualidades a nós atribuídas pelo estereótipo, podemos também ser boas em relação àquelas mais estereotipicamente ligadas ao colonizador. $\mathrm{O}$ estereótipo por si mesmo não impede qualquer exotizado de negociar bens não exóticos, como o conhecimento e a política. Assim, permanecer dentro dos limites impostos (ou sugeridos) pela exoticização depende de fatores que vão além da exotização em si, por exemplo, aparência física e classe social; do contrário, como explicar fenômenos como Gisele Bündchen?

\section{Referências bibliográficas}

ANDERSON, Benedict. Imagined Communities. New York, Verso, 1994.

APARICIO, Frances R. and CHÁvEZ-SILVERMAN, Susana. Introduction. In: Tropicalizations: Transcultural Representations of Latinidad. Hanover and London, University Press of New England, 1997.

Augras, Monique. Imaginária França Antártica. Estudos Históricos 4(7), Rio de Janeiro, 1991, pp.19-34.

BESERRA, Bernadete. From Brazilians to Latinos? Racialization and Latinidad in the Making of Brazilian Carnival in Los Angeles. Latino Studies 3(1), 2005a, pp.53-75.

. Negotiating Latinidade in Los Angeles: The Case of Brazilian Immigrants. In: OCHOA, Enrique C.; OCHOA, Gilda L. (orgs.) Latino Los Angeles: Transformations, Communities, and Activism. Tucson, University of Arizona Press, 2005b, pp.24-48.

Brazilian Immigrants in the United States: Cultural Imperialism and Social Class. New York, LFB Scholarly Publishing, 2003.

Brazilians in Los Angeles: Imperialism, Immigration, and Social Class. Tese de Doutorado, University of California, Riverside, 2000a.

A integração brasileira no mundo latino de Los Angeles. XXIV Encontro da ANPOCS, Petrópolis-RJ, 2000b. 
Move your Body! Brazilian Carnival Takes over the World. Brazzil 10(158):19-24, 1999.

. Keeping the Flame: Brazilian Gauchos in Los Angeles. Brazzil 10(156), 1998, pp.26-27.

Buarque de Holanda, Sérgio. Raízes do Brasil. São Paulo, Companhia das Letras, 2003.

. Visão do Paraíso - Os Motivos Edênicos no Descobrimento e Colonização do Brasil. São Paulo, Folha de S.Paulo/Brasiliense, 2000.

Casalla, Mario. America Latina en Perspectiva: Dramas del pasado, huellas del present. Buenos Aires, Altamira, 2003.

Collins Hill, Patricia. Black Feminist Thought. Boston, Unwin Hyman, 1990.

DAMATTA, Roberto. O que faz o Brasil, Brasil? Rio de Janeiro, Salamandra, 1984.

Relativizando: Uma Introdução à Antropologia Social. Petrópolis-RJ, Vozes, 1981.

DAVIS, Darien. Before We Called This Place Home:Precursors of the Brazilians Community in the United States. I National Conference on Brazilian Immigration to the United States. Cambridge, Mass., 2005.

. The Brazilian-Americans: Demography and Identity of An Emerging Latino Minority. The Latino Review of Books 3(1-2), 1997a, pp.8-15.

To Be or Not to Be Brazilian: Carmen Miranda's Quest for Fame and 'Authenticity' in the United States. Paper presented at the IV Meeting of the Brazilian Studies Association, Washington, DC, $1997 b$.

DE LOURENÇO, Cileine. The Politics of (not)Belonging. In: Giving Voice to a Nascent Community: Exploring Brazilian Immigration Through Research and Practice. Harvard Rockefeller Center for Latin American Studies Working Papers Series, 2004.

Del PRIORE, Mary L. M. Retrato da América quando jovem: imagem e representações sobre o novo continente entre os séculos XVI e XVII. Estudos Históricos, vol. 5, n 9, Rio de Janeiro, Fundação Banco do Brasil, 1992. 
Sob a sombra de Carmen Miranda e do carnaval

DELENEAU, Jean. Uma história do paraíso. O jardim das delícias. Lisboa, Terramar, 1992.

ESPINOZA, Rodolfo. Pleasure Principle. Brazzil 9 (142)13-21, 1997.

FANON, Franz. Black Skin White Masks. New York, Grove Press, 1967. . The Wretched of the Earth. New York: Grove Press, 1963.

FRANZINE, Fábio. As Raízes do País do Futebol: Estudo sobre a relação entre o futebol e a nacionalidade brasileira (1919-1950). Dissertação de Mestrado em História Social, USP, 2000.

FREYRE, Gilberto. The Masters and the Slaves. Berkeley, University of California Press, 1946.

GozA, Franklin. Brazilian Immigration to North America. International Migration Review 28, 1994, pp.136-152.

KEARNEY, Michael e BESERRA, Bernadete. Migration and Identities: A Class-Based Approach. Latin American Perspectives 31(5), 2004, pp.3-14.

LARRAIN, Jorge. Ideology and Cultural Identity - Modernity and the Third World Presence. Cambridge, Polity Press, 1994.

McCann, Bryan. Hello, hello Brazil - Popular Music in the Making of Modern Brazil. Durham-NC, Duke University Press, 2004.

MACHADO, Igor J. R. Estado-nação, identidade-para-o-mercado e representações de nação. Revista de Antropologia 47 (1), 2004.

MARGOLIS, Maxine. Brazilians and the 1990 United States Census: Immigrants, Ethnicity, and the Undercount. Human Organization 54(1), 1995, pp.52-59.

Little Brazil - An Ethnography of Brazilian Immigrants in New York City. Princeton-NJ, Princeton University Press, 1994.

MARTES, Ana C. B. Brasileiros nos Estados Unidos: Um estudo sobre imigrantes em Massachusetts. São Paulo, Paz e Terra, 1999.

Memmi, Albert. The Colonizer and the Colonized. Boston, Beacon Press, 1991.

MENEZES, Eduardo Diatahy Bezerra de. A Cultura Brasileira "Descobre" o Brasil ou "Que País é Este?!", uma Pergunta à Cata de Resposta. Dossiê Quinhentos Anos de América, no 12, dez./91-fev./92, pp.7693. 
OBOLER, Suzanne. The Politics of Labeling: Latino/a Cultural Identities of Self and Others. Latin American Perspectives 19(4), 1992, pp.18-36.

Oliven, Ruben. Tradition Matters: Modern Gaucho Identity in Brazil. New York, Columbia University Press, 1996.

ORTIZ, Renato. Cultura Brasileira e Identidade Nacional. São Paulo, Brasiliense, 1985.

PAGE, Joseph. The Brazilians. New York, Addison-Wesley Publishing Company, 1995.

Prasso, Sheridan. The Asian Mystique - Dragon Ladies, Geisha Girls, and Our Fantasies of the Exotic Orient. New York, Public Affair, 2005.

Ribeiro, Darcy. O Povo Brasileiro: A Formação e o Sentido do Brasil. São Paulo, Companhia das Letras, 1999.

RIBEIRO, Gustavo. Street Samba: Carnaval and Transnational Identities in San Francisco. Paper presented at the IV Conference of Brazilian Studies Association, Washington, DC, 1997.

RIEDINGER, E. Brazilian Americans, An Emerging Hispanic Group in the United States. Paper presented at the IV Conference of Brazilian Studies Association, Washington, DC, 1997.

SAID, Edward. Culture and Imperialism. New York, Vintage Books, 1994. . Orientalism. New York, Vintage Books, 1979.

SALES, Teresa. Brasileiros Longe de Casa. São Paulo, Cortez Editora, 1999.

Savigliano, Marta. Tango and the Political Economy of Passion. Boulder, Westview Press, 1995.

SINHA, Mrinalini. Colonial Masculinity: The 'Manly Englishman' and the Effeminate Bengali' in the Late Nineteenth Century. Manchester and New York, Manchester University Press, 1995.

Todorov, Tzvetan. On Human Diversity - Nationalism, Racism, and Exoticism in French Thought. Cambridge, Mass., Harvard University Press, 1993.

TORRESAN, Angela. Quem Parte, Quem Fica: uma Etnografia sobre migrantes Brasileiros em Londres. Dissertação de Mestrado, Museu Nacional, Universidade Federal do Rio de Janeiro, 1994. 
Sob a sombra de Carmen Miranda e do carnaval

TosTA, Antonio L. Latino, eu? The Paradoxical Interplay of Identity in Brazuca Literature. Hispania 87(3), 2004, pp.576-585.

TURNER, Frederik. O espírito ocidental contra a natureza: mito, história e terras selvagens. Rio de Janeiro, Campus, 1990. 